\title{
Iron status in pregnant women in the Republic of Seychelles
}

\author{
Emeir M Duffy ${ }^{1, *}$, Maxine P Bonham ${ }^{1}$, Julie MW Wallace ${ }^{1}$, Chin-Kuo Chang ${ }^{1}$, \\ Paula J Robson ${ }^{1}$, Gary J Myers², Philip W Davidson², Thomas W Clarkson ${ }^{3}$, \\ Conrad F Shamlaye ${ }^{4}$ and JJ Strain ${ }^{1}$ \\ ${ }^{1}$ Northern Ireland Centre for Food and Health (NICHE), School of Biomedical Sciences, University of Ulster, \\ Coleraine BT52 1SA, UK: ${ }^{2}$ Division of Child Neurology, University of Rochester School of Medicine and \\ Dentistry, Rochester, NY, USA: ${ }^{3}$ Department of Environmental Medicine, University of Rochester, Rochester, NY, \\ USA: ${ }^{4}$ Ministry of Health, Victoria, Mahé, Republic of Seychelles
}

Submitted 20 August 2008: Accepted 25 June 2009: First published online 26 August 2009

\begin{abstract}
Objective: To establish the Fe status of pregnant women and their neonates in the Republic of Seychelles.

Design: A prospective study.

Setting: Republic of Seychelles.

Subjects: Pregnant women were recruited and blood samples taken at enrolment and post-delivery along with cord blood samples. Ferritin and soluble transferrin receptor (sTfR) were measured in maternal $(n$ 220) and cord blood ( $n$ 123) samples.

Results: Maternal Fe deficiency (ferritin $<15 \mathrm{ng} / \mathrm{ml}$, sTfR $>28 \mathrm{nmol} / \mathrm{l}$ ) was present in $6 \%$ of subjects at enrolment and in $20 \%$ at delivery. There was no significant decrease in maternal ferritin. A significant increase in sTfR was observed between enrolment and delivery $(P<0 \cdot 001)$. Maternal BMI and use of Fe supplements at 28 weeks' gestation were associated with improved maternal Fe status at delivery, whereas parity had a negative effect on STfR and ferritin at delivery.

Conclusions: Fe status of pregnant Seychellois women was, on average, within normal ranges. The incidence of Fe deficiency throughout pregnancy in this population was similar to that in a Westernised population. Increased awareness of the importance of adequate Fe intake during pregnancy, particularly in multiparous women, is warranted.
\end{abstract}

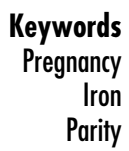

Fe is an essential nutrient throughout the life cycle. Maternal Fe status is particularly important during pregnancy, where increased demands are placed on Fe stores in order to supply the growing fetus and placenta and to sustain the associated biological changes ${ }^{(1)}$. Fe requirements and $\mathrm{Fe}$ absorption rates, owing to the cessation of menses, are decreased in the first trimester of pregnancy but rise progressively during the second and third trimesters.

Fe deficiency remains the most common nutritional deficiency in the world ${ }^{(2)}$ and Fe-deficiency anaemia (IDA) is the most common nutritional deficiency in pregnancy, particularly in developing countries ${ }^{(1,3)}$. The generally accepted cut-off level for $\mathrm{Hb}$ and serum ferritin, below which Fe stores are considered to be depleted, are $<11 \cdot 0 \mathrm{~g} / \mathrm{dl}$ and $<15 \mathrm{ng} / \mathrm{ml}$, respectively ${ }^{(4)}$. Estimates from the WHO report that nearly half of pregnant women in the world are anaemic with an estimated $52 \%$ in non-industrialized as compared with $23 \%$ in industrialized countries $^{(4)}$; the latter having increased from the $18 \%$ prevalence reported in $1992^{(5)}$. At least $50 \%$ of anaemia cases during pregnancy are attributable to $\mathrm{Fe}$ deficiency $^{(2,6)}$. Anaemia is particularly prominent in Asia, with an estimate of $44 \%$ in non-pregnant and $60 \%$ in pregnant women ${ }^{(7)}$, and throughout Africa, where about $40 \%$ of non-pregnant and $50 \%$ of pregnant women are anaemic; West Africa is the most affected and Southern Africa the least ${ }^{(4,5)}$.

The prevalence of Fe deficiency is far greater than the prevalence of anaemia ${ }^{(8)}$ and Fe deficiency often develops in a later stage of pregnancy even among those who enter pregnancy with relatively adequate $\mathrm{Fe}$ stores ${ }^{(9)}$. There is conflicting evidence as to whether maternal Fe deficiency results in fetal Fe deficiency. Some studies suggest that fetal Fe stores are maintained irrespective of maternal Fe status $^{(10,11)}$, whereas others report that maternal Fe deficiency can cause depletion of fetal Fe stores $^{(\mathcal{9}, 11)}$.

Fe deficiency during pregnancy has been associated with multiple adverse outcomes for both mother and infant, including an increased risk of haemorrhage, sepsis, maternal mortality, perinatal mortality and low birth weight $^{(1,12-18)}$. Fe deficiency in neonates may have negative effects on cognitive development and immune functioning and is associated with increased infant morbidity rates ${ }^{(19-21)}$.

In the present study, we examined Fe status during pregnancy in the Republic of Seychelles, a small island 
developing state located in the Indian Ocean, approximately 1000 miles east of Mombasa, Kenya. In 1961 the prevalence of anaemia in women in the Seychelles was reported as being $3 \cdot 1 \%(\mathrm{Hb}<80 \mathrm{~g} / \mathrm{l})^{(22)}$. Given the importance of Fe status during pregnancy, it is important to ascertain current information regarding the Fe status of pregnant women residing in the Seychelles. The prevalence of Fe deficiency during pregnancy in this population was determined, and its relationships with gestational age, parity, birth weight and birth length were investigated.

\section{Subjects and methods}

\section{Subjects and design}

This study forms part of a larger prospective study - the Seychelles Child Development Nutrition Study (SCDNS). A total of 300 pregnant women were recruited in 2001 from all nine antenatal clinics on the island of Mahé, the main island of the Republic of Seychelles. At their first antenatal visit, women were invited to participate in the study and all volunteers gave written consent in accordance with the Helsinki Declaration. Inclusion criteria were aged over 16 years, resident on Mahé and nativeborn Seychellois. Subjects were excluded if they were vegetarian, or if they had a serious medical illness such as insulin-dependent diabetes, toxaemia with seizures or a haematological disorder such as thalassaemia or sickle cell anaemia. Participants completed a number of questionnaires requesting information on health and lifestyle factors including use of $\mathrm{Fe}$ supplements, parity and smoking. All pregnant women in the Republic of Seychelles are routinely advised to take one tablet containing $200 \mathrm{mg} \mathrm{FeSO}_{4}$ (equivalent to $65 \mathrm{mg} \mathrm{Fe}(\mathrm{II})$ ) and $0 \cdot 25 \mathrm{mg}$ folic acid each day during pregnancy. Supplements are provided free of charge. The study was reviewed and approved by the Seychelles Research Ethics Committee.

\section{Blood collection}

Pregnant women had non-fasting blood samples collected at enrolment, 28 weeks and at delivery. Cord blood samples were also collected immediately after delivery. Blood samples were collected into plain serum tubes and immediately stored at $4^{\circ} \mathrm{C}$ until centrifugation within $3 \mathrm{~h}$ of collection at $1000 \mathrm{~g}$ for $15 \mathrm{~min}$. Serum was stored at $-80^{\circ} \mathrm{C}$ until analysis. Samples were accompanied and transported on dry ice for batch analysis at the University of Ulster.

\section{Antbropometry and obstetric measurements}

All measuring equipment was calibrated prior to initiation of the study, and regularly throughout the study, by the Seychelles Bureau of Standards. Maternal height and weight were measured by trained nurses at enrolment and used to calculate BMI. Neonatal weight and length were measured by trained nurses at birth. Birth weight less than $2500 \mathrm{~g}$ was considered low birth weight and gestational age of less than 37 weeks was considered as preterm delivery.

\section{Dietary assessment}

At 28 weeks' gestation, a $4 \mathrm{~d}$ (two consecutive weekdays and two weekend days) semi-quantitative diet diary was administered to provide detailed dietary information including that of dietary Fe intake. Foods and beverages reported in the diet diaries were analysed using the dietary analysis package WISP version $2 \cdot 0$ (Tinuviel Software, Warrington, UK). The dietary analysis package was supplemented with food composition and recipe data for foods consumed in the Republic of Seychelles that were not available in $\operatorname{WISP}^{(23,24)}$. The basic nutrient composition of the ten most commonly consumed fish in the Republic of Seychelles was analysed (CCFRA Technology Ltd, Chipping Campden, UK) and nutrient values added to the WISP database. A more detailed description of dietary collection and analysis in SCDNS, including the incidence of under-reporting, is described elsewhere ${ }^{(25)}$.

\section{Biochemical analysis}

Assessment of soluble transferrin receptor (sTfR) status alongside the more traditional Fe status marker, ferritin, was carried out in both maternal and cord blood samples. Ferritin was assessed in serum via an automated enzyme immunoassay (United Hospitals H \& SS Trust, Antrim, UK). The normal reference range for ferritin within this laboratory is between 15 and $300 \mathrm{ng} / \mathrm{ml}$ and maternal ferritin level $<15 \mathrm{ng} / \mathrm{ml}$ was used as a cut-off for Fe deficiency ${ }^{(4)}$. Cord blood ferritin cut-off values of 60 and $35 \mathrm{ng} / \mathrm{ml}$ were taken as defining decreased and severely depleted fetal Fe stores respectively ${ }^{(6)}$. The concentration of sTfR was quantified in serum using an ELISA method (R\&D Systems Europe Ltd, Oxon, UK). The normal range, according to the manufacturer's instructions, is between 8.7 and $28.1 \mathrm{nmol} / 1$. Total body Fe (TBI) was calculated from the ratio of sTfR to serum ferritin (R:F ratio) according to the equation devised by Cook et $a l^{(26)}$ and was expressed as the Fe surplus in stores (positive value) or the Fe deficit in tissues (negative value). Serum Creactive protein (CRP) was measured at 28 weeks' gestation using an automated I-Lab 600 technique (BIOKIT SA, Barcelona, Spain). CRP is a non-specific indicator of inflammation and is considered normal when $<6 \mathrm{mg} / \mathrm{l}$.

A combination of haematological and biochemical markers of Fe status is recommended to define Fe deficiency in a population ${ }^{(27,28)}$. The combination of ferritin $<15 \mathrm{ng} / \mathrm{ml}$ and sTfR $>28 \cdot 1 \mathrm{nmol} / \mathrm{l}$ was taken to represent maternal Fe deficiency in this cohort. Fe deficiency in cord blood was defined as having both ferritin $<60 \mathrm{ng} / \mathrm{ml}$ and sTfR $>28 \cdot 1 \mathrm{nmol} / \mathrm{l}$.

\section{Statistical analysis}

All data were analysed using the SPSS for Windows statistical software package version $13 \cdot 0$ (SPSS Inc., Chicago, 
IL, USA) and the significance level ( $\alpha$ level) was set as $0 \cdot 05$. Data for all variables were tested for normality using the Kolmogorov-Smirnov test and the variables not showing normal distribution were log-transformed prior to statistical analysis. Power calculations were carried out for the primary analysis and are outlined elsewhere ${ }^{(29)}$. Power calculations were based on a sample size to detect a 5-point difference on the Bayley Scales of Infant Development (BSID-II). The calculation indicated that a sample size of 250 subjects would afford an $80 \%$ power to detect a 5-point difference between low and high MeHg exposure groups using a two-sided test and a significance level of $0 \cdot 05^{(29)}$.

The change in ferritin and sTfR between enrolment and delivery was analysed using a mixed model analysis adjusting for maternal age, maternal BMI, gestational age, use of Fe supplements at 28 weeks' gestation, smoking, parity and dietary Fe intake. Linear regression models were used to detect the factors which determined the change in STfR and ferritin between enrolment and delivery. Separately, ferritin and sTfR were treated as dependent variables in univariate analyses to estimate the effect of each variable and then in multivariate analysis for confounding control by the consideration of well-characterised factors that affect Fe status during pregnancy and those found to be significant following univariate analysis. These factors were maternal age, maternal BMI, smoking, sex of baby, use of $\mathrm{Fe}$ supplements at 28 weeks' gestation, gestational age, parity, dietary Fe intake and CRP. Beta values with $95 \%$ confidence intervals were estimated for the effects of these predicting factors. In multivariate analysis, maternal age and gestational age were considered confounders, although non-significant effects were found in univariate analysis. Similarly, linear models were used to detect the factors which determined cord blood ferritin and sTfR, including maternal ferritin and sTfR. Cord blood ferritin and sTfR levels were treated as dependent variables in univariate analyses to estimate the effect of each variable and then in multivariate analysis for confounding control by the consideration of factors that affect cord blood $\mathrm{Fe}$ status and those found to be significant following univariate analysis. These factors were maternal ferritin, maternal sTfR, maternal age, maternal BMI, smoking, sex of baby, use of Fe supplements at 28 weeks' gestation, gestational age, parity, dietary Fe intake and CRP. Beta values with 95\% confidence intervals were estimated for the effects of these predicting factors.

Associations among maternal Fe status measures, newborn Fe status measures and neonatal anthropometric outcomes were analysed using linear regression controlling for maternal age, maternal BMI, use of $\mathrm{Fe}$ supplements at 28 weeks' gestation and parity.

\section{Results}

From the original 300 subjects recruited, twenty-four were excluded because of miscarriage, neonatal death, nonpregnant, delivery of twins or delivery overseas ${ }^{(29)}$. Enrolment subject data were available for 276 subjects of which complete data sets for maternal Fe status measures were available for 220 subjects. Data on infant Fe status were available for a subset ( $n$ 123) of subjects.

\section{Subject characteristics and dietary data}

The mean (SD) gestational age at enrolment was $12 \cdot 7(4 \cdot 4)$ weeks. The mean (SD) gestational age at delivery was $38.8(1 \cdot 4)$ weeks with some $6 \%(n 14)$ having preterm births; the latter having a mean (SD) gestational age of $35 \cdot 4(0 \cdot 8)$ weeks. Maternal and newborn characteristics are outlined in Table 1 . There was no significant difference in Fe status measures between those reporting $\mathrm{Fe}$ supplement usage at enrolment or at delivery when compared with non-users. The mean (SD) dietary intake of Fe, estimated from the diet diaries, was $9.5(3 \cdot 1) \mathrm{mg} / \mathrm{d}$. The main foods contributing to Fe intake were vegetables

Table 1 Subject characteristics: pregnant women and their neonates in the Republic of Seychelles

\begin{tabular}{|c|c|c|}
\hline & Mean or $n$ & $\%$ or SD \\
\hline \multicolumn{3}{|l|}{ Maternal characteristics ( $n$ 220) } \\
\hline Age (years), mean and sD & $26 \cdot 9$ & $6 \cdot 3$ \\
\hline BMl at enrolment $\left(\mathrm{kg} / \mathrm{m}^{2}\right)$, mean and SD & $26 \cdot 1$ & $6 \cdot 4$ \\
\hline Smokers at enrolment, $n$ and \% & 10 & 4.5 \\
\hline First pregnancy, $n$ and \% & 80 & $36 \cdot 4$ \\
\hline Parity $2-4$ children, $n$ and $\%$ & 117 & $53 \cdot 2$ \\
\hline Parity $\geq 5$ children, $n$ and $\%$ & 23 & $10 \cdot 5$ \\
\hline Parity, mode and \% & $1 \cdot 0$ & $36 \cdot 4$ \\
\hline Use of Fe supplements at enrolment, $n$ and $\%$ & 50 & $22 \cdot 7$ \\
\hline Use of Fe supplements at week $28, n$ and \% & 178 & $80 \cdot 9$ \\
\hline Dietary intake of $\mathrm{Fe}(\mathrm{mg} / \mathrm{d})$, mean and SD & $9 \cdot 5$ & $3 \cdot 1$ \\
\hline Dietary intake of vitamin $C(\mathrm{mg} / \mathrm{d})$, mean and SD & $144 \cdot 1$ & $77 \cdot 3$ \\
\hline \multicolumn{3}{|l|}{ Neonatal characteristics ( $n$ 123) } \\
\hline Gender of infant (ratio of females to males) & $1: 1 \cdot 2$ & \\
\hline Weight $(\mathrm{g})$, mean and SD & $3319 \cdot 5$ & $450 \cdot 9$ \\
\hline Length $(\mathrm{cm})$, mean and SD & $51 \cdot 5$ & $2 \cdot 5$ \\
\hline Head circumference $(\mathrm{cm})$, mean and SD & $33 \cdot 73$ & $1 \cdot 4$ \\
\hline
\end{tabular}


Table 2 Indicators of iron status in pregnant women $(n 220)$ and their neonates $(n 123)$ in the Republic of Seychelles

\begin{tabular}{|c|c|c|c|}
\hline & Enrolment & Delivery & Cordt \\
\hline \multicolumn{4}{|c|}{ Ferritin (normal range: $15-300 \mathrm{ng} / \mathrm{ml}$ ) } \\
\hline Mean & $50 \cdot 2$ & $39 \cdot 4$ & $118 \cdot 3$ \\
\hline SD & $49 \cdot 4$ & $42 \cdot 1$ & $87 \cdot 3$ \\
\hline $95 \% \mathrm{Cl}$ & $43 \cdot 6,56 \cdot 7$ & $33 \cdot 8,45 \cdot 0$ & $102 \cdot 8,133 \cdot 9$ \\
\hline \multicolumn{4}{|c|}{ sTfR (normal range: $8 \cdot 7-28 \cdot 1 \mathrm{nmol} / \mathrm{l}$ ) } \\
\hline Mean & $23 \cdot 0$ & $36 \cdot 6^{\star}$ & 53.9 \\
\hline $\mathrm{SD}$ & $7 \cdot 0$ & $17 \cdot 2$ & $19 \cdot 4$ \\
\hline $95 \% \mathrm{Cl}$ & $22 \cdot 1,23 \cdot 9$ & $34 \cdot 3,38 \cdot 9$ & $50 \cdot 5,57 \cdot 4$ \\
\hline \multicolumn{4}{|c|}{ TBI (normal range: $>0 \mathrm{mg} / \mathrm{kg}$ ) } \\
\hline Mean & $6 \cdot 4$ & $7 \cdot 0$ & $15 \cdot 1$ \\
\hline SD & $3 \cdot 3$ & $2 \cdot 6$ & $5 \cdot 4$ \\
\hline $95 \% \mathrm{Cl}$ & $5 \cdot 9,6 \cdot 8$ & $6 \cdot 7,7 \cdot 4$ & $14 \cdot 1,16 \cdot 0$ \\
\hline
\end{tabular}

sTfR, soluble transferrin receptor; TBI, total body Fe.

* Significant difference between enrolment and delivery $(P<0.05)$. Difference tested using a mixed model analysis adjusted for maternal age, maternal BMI, length of gestation, use of Fe supplements, Fe intake and parity.

tNormal range for cord blood may vary from maternal blood.

$(24 \cdot 3 \%)$, bread $(14 \cdot 8 \%)$, meat and meat products $(11 \cdot 6 \%)$ and fish $(8 \cdot 7 \%)$. The mean (SD) dietary intake of vitamin C was $144 \cdot 1(77 \cdot 3) \mathrm{mg} / \mathrm{d}$.

\section{Biochemical analysis}

Mean, SD and 95\% CI for maternal and neonatal ferritin, sTfR and TBI are presented in Table 2. There was no significant difference in ferritin concentrations between enrolment and delivery. However, 19\% of individuals were below the cut-off value of $15 \mathrm{ng} / \mathrm{ml}$ for ferritin at enrolment and this increased to $24 \%$ at delivery. Some $29 \%$ and $11 \%$ of cord ferritin values fell below the cut-off value of $60 \mathrm{ng} / \mathrm{ml}$ (depleted) and $35 \mathrm{ng} / \mathrm{ml}$ (severely depleted), respectively. There was a significant difference in sTfR between enrolment and delivery $(P<0 \cdot 001)$ and the percentage of individuals with sTfR above the cut-off value, $28 \cdot 1 \mathrm{nmol} / 1$, increased from $21 \%$ at enrolment to $63 \%$ at delivery. Some $93 \%$ of cord blood samples had $\mathrm{sTfR}>28 \cdot 1 \mathrm{nmol} / 1$.

\section{Fe deficiency}

At enrolment, $6 \%$ of subjects had both serum ferritin $<15 \mathrm{ng} / \mathrm{ml}$ and sTfR $>28.1 \mathrm{nmol} / \mathrm{l}$; at delivery the number of subjects classified as Fe-deficient had increased to $20 \%$. A total of $28 \%$ of cord blood had both ferritin $<60 \mathrm{ng} / \mathrm{ml}$ and STfR $>28 \cdot 1 \mathrm{nmol} / \mathrm{l}$, while $10 \% \mathrm{had}$ ferritin $<35 \mathrm{ng} / \mathrm{ml}$ and $\mathrm{sTfR}>28 \cdot 1 \mathrm{nmol} / \mathrm{l}$, the latter indicating severe $\mathrm{Fe}$ deficiency. Maternal Fe deficiency at enrolment was not associated with the Fe status of the neonates; however, those mothers who were Fe-deficient at delivery ( $n$ 30) had neonates with significantly lower serum ferritin $(P=0.005)$ than those non-deficient at delivery ( $n$ 93).

\section{Predictors of maternal Fe status and cord Fe status}

Multivariate analysis revealed significant effects of maternal BMI $(\beta=-0 \cdot 72,95 \%$ CI $-1 \cdot 05,-0 \cdot 39)$, use of Fe supplements at 28 weeks' gestation $(\beta=-10 \cdot 78,95 \%$ CI $-16 \cdot 02,-5 \cdot 54)$, first pregnancy $(\beta=-8 \cdot 03,95 \%$ CI
$-12 \cdot 67,-3 \cdot 39)$ and parity $(\beta=2 \cdot 38,95 \%$ CI $1 \cdot 13,3 \cdot 64)$ on maternal sTfR. Parity was a significant factor on change in maternal ferritin levels over pregnancy $(\beta=-5 \cdot 38,95 \% \mathrm{CI}-10 \cdot 44,-0 \cdot 31)$. No factor was found to have a significant effect on cord sTfR or ferritin. A significant negative correlation was seen between STfR at delivery and cord ferritin $(r=-0 \cdot 190 ; P=0 \cdot 035)$. No association was seen between any maternal Fe status measure and birth weight, length or gestational age.

\section{Discussion}

Findings reported here would suggest that the incidence of Fe deficiency in pregnancy in this cohort is similar to that reported in industrialized countries and that the Fe status of pregnant women in Seychelles was on average within the normal range. Maternal BMI, use of Fe supplements at 28 weeks' gestation and parity were important predictors of Fe status in this cohort. Maternal Fe status, particularly sTfR and ferritin at delivery, was associated with neonatal $\mathrm{Fe}$ status. Our results would support the importance of adequate Fe status in the final trimester to ensure adequate neonatal stores are achieved.

Using a combination of maternal ferritin and sTfR measures, a total of $6 \%$ of this cohort was Fe-deficient in early pregnancy, a figure which increased to $20 \%$ at delivery. As Fe deficiency precedes IDA and therefore is more common ${ }^{(8)}$, we would estimate that IDA would be present in less than $20 \%$ of this cohort, a percentage which is comparable to that reported for developed industrialised countries in which anaemia during pregnancy averages $23 \%^{(4,8,30)}$ and similar to the prevalence of $18 \%$ reported by WHO in $1992^{(5)}$. In 1961 the prevalence of anaemia in women in the Seychelles was reported as being $3 \cdot 1 \%(\mathrm{Hb}<80 \mathrm{~g} / 1)^{(22)}$. As $6 \%$ of women enrolled to the present study had Fe deficiency, it is possible that a similar proportion of women had IDA to that reported previously. 
Mean maternal ferritin in this cohort at enrolment was $50 \cdot 2 \mathrm{ng} / \mathrm{ml}$, considerably higher than those reported in other studies of Fe status in pregnancy where ferritin levels at enrolment ranged from $17 \cdot 5$ to $38.7 \mathrm{ng} / \mathrm{ml}^{(31-33)}$. Indeed, maternal ferritin at delivery in the Republic of Seychelles was comparable to the first-trimester ferritin levels found in these studies and was considerably higher than those reported at delivery in studies where Fe supplementation during pregnancy was investigated ${ }^{(34,35)}$. The population of the Republic of Seychelles is not exposed to significant levels of pollutants such as polychlorinated biphenyls, pesticides or $\mathrm{Pb}$ and it is a malaria-free country ${ }^{(36)}$. Therefore, the ferritin value reported at enrolment is most likely owing to dietary factors rather than an inflammatory response.

Mean enrolment sTfR of $23 \cdot 0 \mathrm{nmol} / 1$ was below the cutoff of $28 \cdot 1 \mathrm{nmol} / 1$ and compared well with those found by others in pregnancy, where values ranging from 12.63 to $24.7 \mathrm{nmol} / 1$ were reported ${ }^{(31,33)}$. Levels of sTfR at delivery reported in this pregnancy cohort of $36.6 \mathrm{nmol} / 1$ were comparable to those reported by others ${ }^{(31,33)}$.

Serum ferritin was not significantly different between enrolment and delivery, albeit there was a significant increase in sTfR. We speculate that the significant increase in STfR may be due to the increased Fe requirement and Fe turnover in the last trimester of pregnancy ${ }^{(37,38)}$. The significant rise in STfR during pregnancy may be a combined result of reduced erythropoiesis in the first trimester along with an increase in erythropoiesis in the later stages of pregnancy and a concurrent development of tissue Fe deficiency ${ }^{(39,40)}$. Nevertheless, TBI remained positive throughout pregnancy in this cohort suggesting that even when erythropoiesis activity was increased maternal $\mathrm{Fe}$ stores were not depleted.

In this cohort, maternal BMI and use of Fe supplements had positive effects on maternal sTfR whereas parity had a negative effect on both maternal sTfR and maternal ferritin. Universal Fe supplementation of pregnant women in the Seychelles is widely advocated and reported usage of $\mathrm{Fe}$ supplements in the present study rose from $23 \%$ at enrolment to $81 \%$ by 28 weeks' gestation. Although there was no significant difference in Fe status measures at enrolment or at delivery between those who reported usage of $\mathrm{Fe}$ supplements and non-users, multivariate analysis would suggest that use of $\mathrm{Fe}$ supplements may have had a small, but significant, benefit to Fe status in this cohort. Dietary analysis of this population revealed an Fe intake of $9.5 \mathrm{mg} / \mathrm{d}^{(25)}$, which falls below the recommended nutrient intake for Fe during pregnancy in the UK of $14.8 \mathrm{mg} / \mathrm{d}$. In the Republic of Seychelles, nutritional guidelines are based on the UK dietary reference values ${ }^{(25)}$. Although dietary $\mathrm{Fe}$ intake observed in the present study was low, the findings are comparable to those in populations in the $\mathrm{UK}^{(41)}$, Mexico $^{(42)}$ and South Africa ${ }^{(43)}$, and the combination of dietary $\mathrm{Fe}$ and $\mathrm{Fe}$ received from supplement use would have provided $74.5 \mathrm{mg} \mathrm{Fe} / \mathrm{d}$.
Other studies support our association of high parity with Fe deficiency ${ }^{(40,44,45)}$. Parity in particular appears to be associated, although not exclusively, with Fe deficiency in studies carried out in developing countries ${ }^{(46-48)}$. It may be particularly important to inform multiparous women in developing countries, such as the Republic of Seychelles, of the importance of adequate Fe intake during pregnancy.

Generally, full-term infants are born with adequate Fe stores in the liver and haematopoietic tissue because of destruction of fetal red blood cells soon after birth. The cord Fe status measures were higher than maternal values which is similar to previous reports, albeit cord ferritin levels reported here of $118 \cdot 3 \mathrm{ng} / \mathrm{ml}$ were on average lower than those reported by others ${ }^{(49-51)}$. In our study, mothers who were classified as Fe-deficient at delivery had neonates with significantly lower serum ferritin than those neonates born to mothers who were not deficient at delivery. This finding has been observed previously $^{(49,52-54)}$ and highlights the importance of maternal Fe status at delivery as a determinant of neonatal ferritin levels. In the present study, maternal sTfR at delivery correlated significantly with neonatal ferritin, further supporting the hypothesis that neonatal Fe stores are dependent on maternal Fe status at delivery. The majority of fetal Fe uptake is after week 30 of gestation, when infant Fe stores are laid down ${ }^{(8)}$. This coincides with an increase in maternal erythropoiesis to maintain maternal Fe status, which is evident in this cohort where increased sTfR was seen at delivery.

The overall health of the nation has changed with improvements in free health care, education and sanitation leading to the Seychelles being ranked 35th in the world on the Human Development Index in 2004 ${ }^{(36)}$. Dietary patterns in Seychelles, however, are in a state of transition with a move towards a Western-style diet. Recent work by our group highlights the importance of fish as a dietary source of $\mathrm{Fe}^{(25)}$. These findings suggest caution in establishing public health policies that promote limitation of fish intake during pregnancy.

The public health message for adequate intake of dietary Fe together with the use of Fe supplementation in pregnancy, especially in the last trimester and in multiparous women, needs to be promoted in the Seychelles to ensure optimal Fe status of the infant.

\section{Acknowledgements}

This paper was in part supported by grants RO1 ES10219, P30 ES01247 and T32 ES007271 from the National Institute of Environmental Health Sciences to the University of Rochester. Additional support was provided by the Republic of Seychelles and the University of Ulster, Northern Ireland. No author has any conflict of interest. E.M.D., M.P.B., J.M.W., P.J.R., G.J.M., P.W.D., T.W.C., 
C.F.S. and J.J.S. were involved in conception of the work, execution of the study and are grant holders. E.M.D. and M.P.B. contributed to the sample analysis. E.M.D., M.P.B., J.M.W., C.-K.C., P.J.R., G.J.M., P.W.D., T.W.C., C.F.S. and J.J.S. contributed to data analysis and writing of the manuscript. The authors would like to thank the midwives, the community health workers and the women who participated in the study.

\section{References}

1. Allen LH (2000) Anemia and iron deficiency: effects on pregnancy outcome. Am J Clin Nutr 71, 5 Suppl., S1280-S1284

2. DeMaeyer EM \& Adiels-Tegman M (1985) The prevalence of anaemia in the world. World Health Stat Q 38, 302-316.

3. Guidotti RJ (2000) Anaemia in pregnancy in developing countries. BJOG 107, 437-438.

4. World Health Organization (2001) Iron Deficiency Anaemia, Assessment, Prevention and Control: A Guide for Programme Managers. http://whqlibdoc.who.int/hq/2001/ WHO_NHD_01.3.pdf (accessed July 2009).

5. World Health Organization (1992) The Prevalence of Anaemia in Women: A Tabulation of Available Information. WHO/MCH/MSM/92.2, 2nd ed. Geneva: WHO, Maternal Health and Safe Motherhood Programme, Division of Family Health.

6. Singla PN, Tyagi M, Shankar R, Dash D \& Kumar A (1996) Fetal iron status in maternal anemia. Acta Paediatr 85, $1327-1330$.

7. Rush D (2000) Nutrition and maternal mortality in the developing world. Am J Clin Nutr 72, 1 Suppl., S212-S240.

8. Allen LH (1997) Pregnancy and iron deficiency: unresolved issues. Nut Rev 55, 91-101.

9. Puolakka J, Janne O, Pakarinen A \& Vihko R (1980) Serum ferritin as a measure of stores during pregnancy and after normal pregnancy with and without iron supplements. Acta Obstet Gynecol Scand Suppl 95, 43-51.

10. Lao TT, Loong EP, Chin RK, Lam CW \& Lam YM (1991) Relationship between newborn and maternal iron status and haematological indices. Biol Neonate 60, 303-307.

11. Olivares M, Llaguno S, Marin V, Hertrampf E, Mena P \& Milad M (1992) Iron status in low-birth-weight infants, small and appropriate for gestational age. A follow up study. Acta Paediatr 81, 824-828.

12. Williams MD \& Wheby MS (1992) Anemia in pregnancy. Med Clin North Am 76, 631-647.

13. Scholl TO, Hediger ML, Fischer RL \& Shearer JW (1992) Anemia vs iron deficiency: increased risk of preterm delivery in a prospective study. Am J Clin Nutr 55, 985-988.

14. Ramussen KM (2001) Is there a causal relationship between iron deficiency or iron deficiency anaemia and weight at birth, length of gestation and perinatal mortality? J Nutr 131, 2 Suppl. 2, S590-S603.

15. Letsky EA (2001) Maternal anaemia in pregnancy, iron and pregnancy - a haematologist's viewpoint. Fetal Matern Med Rev 12, 159-175.

16. Murphy JF, O'Riordan J, Newcombe RJ, Coles EC \& Pearson JF (1986) Relation of haemoglobin levels in the first and second trimester to outcome of pregnancy. Lancet $\mathbf{1}$, 992-995.

17. Steer PJ (2000) Maternal hemoglobin concentration and birth weight. Am J Clin Nutr 71, 5 Suppl., S1285-S1287.

18. Scanlon KS, Yip R, Schieve LA \& Cogswell ME (2000) High and low haemoglobin levels during pregnancy: differential risks for preterm birth and small for gestational age. Obstet Gynecol 96, 741-748.
19. Beard JL (2001) Iron biology in immune function, muscle metabolism and neuronal functioning. J Nutr 131, 2 Suppl. 2, S568-S580.

20. Georgieff MK (2007) Nutrition and the developing brain: nutrient priorities and measurement. Am J Clin Nutr $\mathbf{8 5}$ Suppl., S614-S620.

21. McCann JC \& Ames BN (2007) An overview of evidence for a causal relation between iron deficiency during development and deficits in cognitive or behavioural function. $\mathrm{AmJ}$ Clin Nutr 85, 931-945.

22. Foy H \& Kondi A (1961) Report on incidence, aetiology, treatment and prophylaxis of the anaemias in the Seychelles: a study in iron-deficiency anaemias and ancylostomiasis in the tropics. Ann Trop Med Parasitol 55, 25-45.

23. Sayed N, Frans Y \& Schönfeldt H (1999) Composition of South African Foods: Milk and Milk Products; Eggs; Meat and Meat Products. South Africa: Medical Research Council.

24. Ather N, McLaughlin J \& Taylor G (2003) The Concise New Zealand Food Composition Tables, 6th ed. Palmerston North: New Zealand Institute for Crop and Food Research Limited.

25. Bonham MP, Robson PJ, Duffy EM, Wallace JM, Myers GJ, Davidson PW, Clarkson TW, Shamlaye CF, Strain J \& Livingstone $\mathrm{MB}$ (2008) Contribution of fish to intakes of micronutrients important for fetal development: a dietary survey of pregnant women in the Republic of Seychelles. Public Health Nutr (Epublication ahead of print version).

26. Cook JD, Flowers CH \& Skikne BS (2003) The quantitative assessment of body iron. Blood 101, 3359-3364.

27. Cook JD \& Finch CA (1979) Assessing iron status of a population. Am J Clin Nutr 32, 2115-2119.

28. Expert Scientific Working Group (1985) Summary of a report on assessment of the iron nutritional status of the United States population. Am J Clin Nutr 42, 1318-1330.

29. Davidson PW, Strain JJ, Myers GJ et al. (2008) Neurodevelopmental effects of maternal nutritional status and exposure to methylmercury from eating fish during pregnancy. Neurotoxicology 29, 767-775.

30. Rioux FM \& LeBlanc CP (2007) Iron supplementation during pregnancy: what are the risks and benefits of current practices? A review. Appl Physiol Nutr Metab 32, 282-288.

31. Nybo M, Friis-Hansen L, Felding P \& Milman N (2007) Higher prevalence of anemia among pregnant immigrant women compared to pregnant ethnic Danish women. Ann Hematol 86, 647-651.

32. Choi JW, Kim CS \& Pai SH (2000) Erythropoietic activity and soluble transferrin receptor level in neonates and maternal blood. Acta Paediatr 89, 675-679.

33. Tamura T, Goldenberg RL, Johnston KE, Cliver SP \& Hickey CA (1996) Serum ferritin: a predictor of early spontaneous preterm delivery. Obstet Gynecol 87, 360-365.

34. Madhavan Nair K, Bhaskaram P, Balakrishna N, Ravinder P \& Sesikeran B (2004) Response of hemoglobin, serum ferritin, and serum transferrin receptor during iron supplementation in pregnancy: a prospective study. Nutrition 20, 896-899.

35. Ziaei S, Mehrnia M \& Faghihzadeh S (2008) Iron status markers in nonanemic pregnant women with and without iron supplementation. Int J Gynaecol Obstet 100, 130-132.

36. Shamlaye C, Shamlaye H \& Brewer R (2004) Health in Seychelles: an overview. Seychelles Med Dent J 7, 13-20.

37. Oski FA (1993) Iron deficiency in infancy and childhood. $N$ Engl J Med 29, 190-193.

38. Jung Lee E, Oh EJ, Park YJ, Lee HK \& Kim BK (2002) Soluble transferrin receptor (sTfR), ferritin, and sTfR/log ferritin index in anemic patients with nonhematologic 
malignancy and chronic inflammation. Clin Chem $\mathbf{4 8}$, $1118-1121$

39. Akesson A, Bjellerup P, Berglund M, Bremme K \& Vahter M (1998) Serum transferrin receptor: a specific marker of iron deficiency in pregnancy. Am J Clin Nutr 68 1241-1246.

40. Akesson A, Bjellerup P, Berglund M, Bremme K \& Vahter M (2002) Soluble transferrin receptor: longitudinal assessment from pregnancy to postlactation. Obstet Gynecol 99, 260-266.

41. Mouratidou T, Ford F, Prountzou F \& Fraser R (2006) Dietary assessment of a population of pregnant women in Sheffield, UK. Br J Nutr 96, 929-935.

42. de Lourdes Flores M, Neufeld LM, González-Cossío T, Rivera J, Martorell R \& Ramakrishnan U (2007) Multiple micronutrient supplementation and dietary energy intake in pregnant women. Salud Publica Mex 49, 190-198.

43. Kesa H \& Oldewage-Theron W (2005) Anthropometric indications and nutritional intake of women in the Vaal Triangle, South Africa. Public Health 119, 294-300.

44. Hindmarsh PC, Geary MP, Rodeck CH, Jackson MR \& Kingdom JC (2000) Effect of early maternal iron stores on placental weight and structure. Lancet 356, 719-723.

45. Zimmermann MB \& Hurrell RF (2007) Nutritional iron deficiency. Lancet 370, 511-520.

46. Srivastave S, Mehrotra PK, Srivastave SP \& Siddiqui MK (2002) Some essential elements in maternal and cord blood in relation to birth weight and gestational age of the baby. Biol Trace Elem Res 86, 97-105.
47. Agarwal KN, Agarwal DK, Sharma A et al. (2006) Prevalence of anaemia in pregnant and lactating women in India. Indian J Med Res 124, 173-184.

48. Gibson RS, Abebe Y, Stabler S, Allen RH, Westcott JE, Stoecker BJ, Krebs NF \& Hambidge KM (2008) Zinc, gravida, infection, and iron, but not vitamin B-12 or folate status, predict hemoglobin during pregnancy in Southern Ethiopia. J Nutr 138, 581-586.

49. Gaspar MJ, Ortega RM \& Moreiras O (1993) Relationship between iron status in pregnant women and their newborn babies. Investigation in a Spanish population. Acta Obstet Gynecol Scand 72, 534-537.

50. Milman N, Ibsen KK \& Christensen JM (1987) Serum ferritin and iron status in mothers and newborn infants. Acta Obstet Gynecol Scand 66, 205-211.

51. Zittoun J, Blot I, Hill C, Zittoun R, Papiernik E \& Tchernia G (1983) Iron supplements versus placebo during pregnancy: its effects on iron and folate status on mothers and newborns. Ann Nutr Metab 27, 320-327.

52. Milman N, Agger AO \& Nielson OJ (1994) Iron status markers and serum erythropoietin in 120 mothers and newborn infants. Acta Obstet Gynecol Scand 73, 200-204.

53. Milman N (1996) Serum ferritin in Danes: studies of iron status from infancy to old age, during blood donation and pregnancy. A review. Int J Hematol 63, 103-135.

54. O'Brien KO, Zavaleta N, Abrams SA \& Caulfield LE (2003) Maternal iron status influences iron transfer to the fetus during the third trimester of pregnancy. Am J Clin Nutr 77, 924-930. 